\title{
Qi An Brings Passion and Focus to Electronic and Atomistic Modeling
}

\section{Ann Ritchie}

"Three lessons have been important for me to learn in my career: Be passionate about your research; focus on the most important problems in your field; and think about how your scientific research benefits society," said Qi An, assistant professor in the Department of Chemical and Materials Engineering at the University of Nevada, Reno (UNR). An's recent contributions to the field include co-authoring the September 2020 JOM paper, "Modified Failure

Mechanism of Silicon through Excess Electrons and Holes," on quantum materials for energy efficient computing.

"The JOM paper illustrates that the electron and hole carriers have a significant influence on the mechanical properties of silicon, a semiconductor material. This study suggests that the strength and ductility of inorganic semiconductors may be tuned through electron and hole carriers," An said.

Since 2016, An has taught at UNR, where he conducts research and advises students interested in electronic and atomic modeling. He is focused on computational materials design, structure-properties relationships of materials using electronic and atomistic modeling approaches.

With a devotion to problem-solving and bringing benefits to society through his research, An marks the milestones along his career path based on his research contributions. Those milestones include

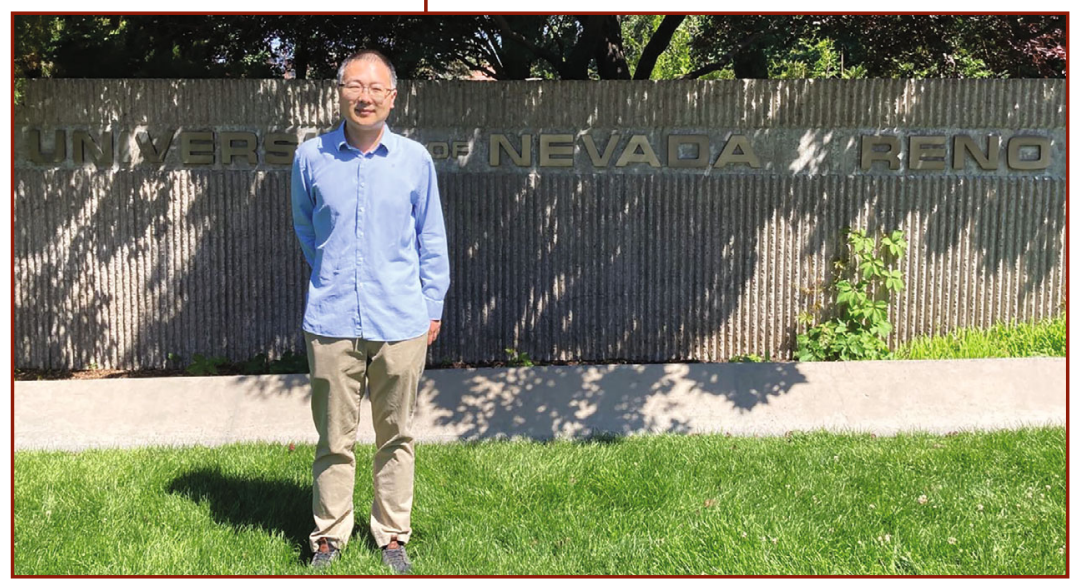

Qi An teaches and researches at the University of Nevada, Reno. three achievements that are distinct in his mind: finding that electron-hole pair excitation plays an important role in determining the dislocation or twinning deformation mechanism of covalent and ionic semiconductors; exploring how the abnormal brittle failure of boron carbide and related superhard ceramics arises from the higher density amorphous shear bands; and determining the catalytic reaction mechanism of the Haber-Bosch process on iron catalysts and developing a hierarchical high-throughput catalyst screening approach to single out silicon as the most promising dopant to improve the efficiency of ironbased catalyst.

An completed doctoral studies at California Institute of Technology (Caltech), where he earned a Ph.D. in materials science in 2012, and then continued research as a postdoctoral scholar in the Division of Chemistry and Chemical Engineering. At Caltech, he especially valued the opportunity to be mentored by William A. Goddard III, who directs the Materials and Process Simulation Center at Caltech. An credits Goddard as having the greatest influence on his career, not only as his Ph.D. advisor but also because he provided "enthusiasm, inspiration, and focus on scientific research."

Through TMS, other mentors and colleagues have helped An along the way. He appreciates being able to expand his networking opportunities with other talented scientists, engineers, and researchers. "TMS provides an excellent opportunity to share my research outcomes with the community, as well as to encourage interactions with experts in my research field," An said.

An is a strong member of the research community and benefits from his own advice to be passionate, stay focused on important problems, and make a societal impact. As An continues to develop and deepen his expertise in computational materials science, his list of contributions to the field only continues to grow. 